\title{
PAPR Reduction in F-OFDM System by using Cluster Scrambling Codeword Shifting
}

\author{
Aidatul Julia Abd Jabar and Azlina Idris
}

\begin{abstract}
Filtered-OFDM (F-OFDM) is one of the proposed candidate for $5 \mathrm{G}$ system. In order to support the diversity in services, it requires the capability to support the multiple asynchronous sub-band transmission. However, the multicarrier transmission systems with different sub-carriers are suffer from high Peak-to-Average Power Ratio (PAPR) of the transmit signal. Consequently, the major problem of the F-OFDM system is the high PAPR value in the system that causing the performance degradation due to the various distortions. This paper presents, a method based on manipulation of the codeword by altering its structure known as Cluster Scrambling Codeword (CSC) is proposed to achieve better PAPR reduction. This is a new formulation on bit data sequence shifting technique, which can give better PAPR reduction compared to conventional scheme. The simulations result show that CSC gives $27.08 \%$ at $7.0 \mathrm{~dB}$ which is better PAPR reduction performance compared to the conventional F-OFDM system.
\end{abstract}

Index Terms- Cluster Scrambling Codeword (CSC), Orthogonal Frequency Division Multiplexing (OFDM), Filtered Orthogonal Frequency Division Multiplexing (F-OFDM), Peak-toAverage Power Ration (PAPR)

\section{INTRODUCTION}

$\mathrm{F}$ ILTERED-OFDM (F-OFDM) implement by $5 \mathrm{G}$ network system a new proposed multicarrier modulation scheme where it introduces to support the diversity in future services and have the capability to support the multiple asynchronous sub-band transmission. The system bandwidth is separated into several sub-bands to a certain width and each sub-band is filtered separately [1]. Basic layout for $5 \mathrm{G}$ system are able to provide facilities such reduced out of band emission and relaxed synchronization [2]. The major problem of the F-OFDM system is the high PAPR value and low performance of the BER in the system which is one major issue faced by every multicarrier modulation technique that cause the performance degradation and high-power consumption due to the various distortions.

This manuscript is submitted on $14^{\text {th }}$ August 2020 and accepted on $14^{\text {th }}$ April 2021. Aidatul Julia Abd Jabar and Azlina Idris are with the School of Electrical Engineering, College of Engineering, Universiti Teknologi MARA, 40450 Shah Alam, Selangor (e-mail: juliajabar@gmail.com, azlina831@uitm.edu.my )

1985-5389/C 2021 The Authors. Published by UiTM Press. This is an open access article under the CC BY-NC-ND license (http://creativecommons.org /licenses/by-nc-nd/4.0/).
An OFDM signal is a high-speed transmission which consists of numbers of independent modulated sub carriers. For OFDM system, the transmit signals may have high peak values in the time domain throughout an OFFT operation since there are several subcarrier components are added. Hence, it is known that OFDM systems have high PAPR compared to the singlecarrier systems. There are two major weaknesses on OFDM systems performance which are high Peak to Average Power Ratio (PAPR) and poor bit error rate (BER) in fading environments when added up coherently. To support the diversity in future services, Filtered-OFDM (F-OFDM) was introduce to be implement by $5 \mathrm{G}$ network system due to the suitable filtering criteria such as flat pass-band over the subcarriers in the sub-band, sharp transition band that minimized the guard bands and sufficient stop-band attenuation [3]. With F-OFDM network system, this will benefit in terms to reduce PAPR and improve BER degradation. As the aim of the F-OFDM system is to get high spectrum efficiency for ultrareliability and low latency communication with larger subcarrier spacing [4].

There are multiple methods that can be used in order to overcome the high PAPR and low BER performance such as the clipping and filtering, selective mapping (SLM), peak windowing and Block Coding Technique [5]. As for the PAPR reduction, there are several methods have been introduced by researcher which is Selective Mapping (SLM), Partial Transmit Sequence (PTS) and codeword shifting [6][7][8]. These are the examples of multiple signaling technique and probabilistic method. Referring to previous study, this is a distortion-less PAPR reduction technique for OFDM system as it is basically using symbol scrambling idea. Multiple signaling is a technique that focus on permutation of multicarrier signal and the signal with lower PAPR value will be selected for transmission while probabilistic technique is focusing on modification of certain parameters in OFDM signal and optimize them to achieve better PAPR reduction [8]. These techniques can achieve significant PAPR reduction without introducing distortion effect.

Throughout this paper, overall of F-OFDM system performance as the promising evolution of $5 \mathrm{G}$ network system will be analyse and evaluate. In order fulfil current user demand on diversity usage and high speed data transmission, the implementation of the scheme that can offer more spectral efficiency with optimal cost become one of the main features to be considered compared to existing 4G OFDM system. Hence, 
a good algorithm is required in order to perform a substantial of PAPR reduction with low computational complexity, better BER performance and with consideration of signal data rate loss problem [9]. This paper proposed a new scheme called the Cluster Scrambling Codeword (CSC) shifting method to deal with high PAPR problem. Main methodological approach is by the manipulation of codeword structure and permutation process is the key to achieve better PAPR reduction by design a new bit sequence technique which that can reduce high PAPR in the F-OFDM system that able generate alternative codeword by altering the codeword structure followed by shifting process. By lowering the codeword shifting distance, it leads to better PAPR as the distance and length relates to the cost of power amplifier in multicarrier communication system.

\section{PEAK-TO-AVERAge PoWER RATIO (PAPR)}

Multicarrier transmission systems with different subcarriers are suffer from high Peak-to-Average Power Ratio (PAPR) of the transmit signal. High value of PAPR signal causes transmitter of front-end high power amplifier (HPA) to suffer of non-linear distortion which leads to saturation of HPA [10]. Thus, the high dynamic range amplifiers are needed which will increase the system cost [11]. With the high value of PAPR, the conversion of OFDM signals from $\mathrm{A} / \mathrm{D}$ and $\mathrm{D} / \mathrm{A}$ will be saturated and this leads to reduction of power consumption efficiency. Additionally, the transmit power amplifier need to be operated in its linear region in order to avoid spectral growth of the multicarrier signal in the form of intermodulation among subcarriers and out-of-band radiation, where the it results to inefficient power conversion.

PAPR of OFDM signals is calculated by the ratio of the peak output power and its average output power [7];

$$
\begin{gathered}
P A P R(d B)=10 \log \left\{\frac{P_{\text {peak }}}{P_{\text {avg }}}\right\} \\
P A P R=\frac{\max _{t}|x(t)|^{2}}{E_{t}\left[|x(t)|^{2}\right]}
\end{gathered}
$$

where signal power average of OFDM system calculated by,

$$
E=\frac{\text { Sum of magnitude of all OFDM symbol }}{\text { No. of OFDM symbol }(N)}
$$

For discrete time signal;

$$
P A P R=\frac{\max _{n}|x(n)|^{2}}{E_{n}\left[|x(n)|^{2}\right]}
$$

An analogue signal is the input signal to the amplifier in the OFDM system and the time domain samples of the output from the inverse fast Fourier transform (IFFT) is $x_{n}$ which represent the transmitted OFDM signals obtained after passing through IFFT operation process on modulated input symbols [12].

$$
x_{n}=\frac{1}{\sqrt{N}} \sum_{k=0}^{N-1} X_{k} W_{N}^{n k}
$$

where $N$ is number of OFDM symbol and $W(k)$ is Additive White Gaussian Noise (AWGN) in frequency domain.

The peak power of received signals is $N$ times the average power when phase values are the same, for an OFDM system with sub-carriers. he amplitude of OFDM signals having a Rayleigh distribution with cumulative distribution given as [12];

$$
F(\gamma)=1-e^{\gamma}
$$

Probability of PAPR that is below certain threshold level, $\gamma$ expressed;

$$
\operatorname{Pr}\{P A P R<\gamma\}=\left(1-e^{-\gamma}\right)^{N}
$$

Complementary Cumulative Distribution Function (CCDF) is commonly presented for PAPR performance, as the number of subcarriers, $N$ increases, PAPR CCDF is increases too;

$$
\begin{gathered}
C C D F(P A P R)=\operatorname{Prob}\left(P A P R>P A P R_{0}\right) \\
C C D F(\gamma)=\operatorname{Pr}\{P A P R>\gamma\}=1-\left(1-e^{-\gamma}\right)^{N}
\end{gathered}
$$

\section{Cluster Scrambling CODEWORd Shifting METHOD}

A new PAPR reduction method is proposed in this paper by using permutation process (circulates shift) in order to generate a scramble data sequence. CSC is focusing on the codeword structure and the bit arrangement as the way to reduce PAPR. By manipulating this two parameters, CSC will produce an alternative codeword having a lower PAPR. Finally, the alternative F-OFDM signal with lowest PAPR value will be chosen for transmitted.

This proposed technique is stimulated by the Artificial Bee Colony (ABC) algorithm as studied in [13][14][15]. The ABC is a swarm based optimization algorithms that having a good PAPR reduction performance [13]. It is simulated based on the behaviour of honeybee mining colonies. Main purposed of $\mathrm{ABC}$ algorithm is to search around the neighbourhood for the best solutions that has mutation operator. A new food source is looked by employed bees and when the honey of the new food source becomes greater than that of the previous food source, it is stored as the possible optimum solutions [15]. On the other hand, this idea also being used in CSC as this proposed technique will select codeword that has the best PAPR value to be transmitted.

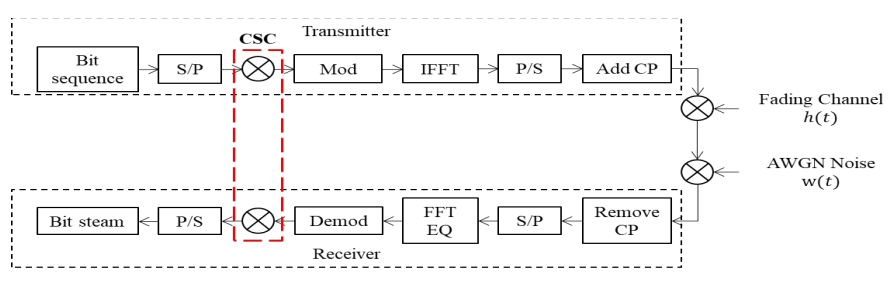

Fig. 1. Block diagram of CSC technique

The formation of OFDM signal for $N$ number of subcarriers begin with the conversion of input data into information symbol 
via serial-to-parallel block process. Then, modulating process will be conducted using 64-QAM and mapped the information symbol into the constellation point. Finally, Inverse Fast Fourier Transform (IFFT) will transform the modulated symbol into an OFDM signal as shown in Fig. 1.

As shown in Fig. 2, $C$ represents the binary sequence codeword having $z$ total number of input bits and can be indicated as $C=\left[C_{1}, C_{2}, \ldots, C_{z}\right]$. The serial to parallel converter will divide the codeword sequence into $p$ number of sub-block denoted by $C^{\prime}=\left[C_{1}^{\prime}, C_{2}^{\prime}, \ldots, C_{p}^{\prime}\right]$. and each sub-block will have $r$ number of bits per symbol where $p=z / r$.

For the first step, is by altering the structure of the codewords into few cluster grouping that is within 2 columns. As for the example shows on Fig. 2, with 4 codewords it is divided into 2 parts which is part $\mathrm{A}$ and part $\mathrm{B}$. Then for the second alternative codeword, it can be obtained by shifting the codeword position in part $\mathrm{B}$ while remain idle the codeword on part A.

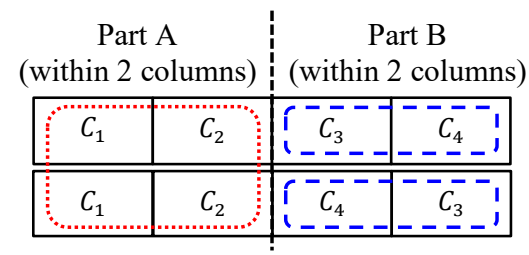

Fig. 2. Example cluster grouping for 4 codewords

By altering the structure of the codeword has a significant impact on PAPR performance lower codeword distance will lead to better PAPR reduction. The advantage of shifting process in CSC is that it can generates an alternative codeword flexibility to the system to choose signal with lower PAPR to be transmitted. Meanwhile, conventional OFDM because it has only one output signal. For better interpretation, the alternative positions bits of codewords for numbers of shifting process is shown in Table 1. Therefore, the alternative OFDM transmitted signal given as;

$$
x^{\prime}(n)=\frac{1}{\sqrt{N}} \sum_{k=0}^{N-1} C_{k}^{\prime} W_{N}^{n k}
$$

where $N$ is number of OFDM symbol and $W(k)$ is Additive White Gaussian Noise (AWGN) in frequency domain

TABLE I

Bit ARRANGEMENT OF CODEWORd For CSC TECHNIQUe FOR 64-QAM (6 CODEWORDS)

\begin{tabular}{cc}
\hline \hline Sub block codeword bits & Position of bits \\
\hline Codeword & $\mathrm{C}_{1}, \mathrm{C}_{2}, \mathrm{C}_{3}, \mathrm{C}_{4}, \mathrm{C}_{5}, \mathrm{C}_{6}$ \\
Codeword Shift 1 & $\mathrm{C}_{1}, \mathrm{C}_{2}, \mathrm{C}_{3}, \mathrm{C}_{4}, \mathrm{C}_{6}, \mathrm{C}_{5}$ \\
Codeword Shift 2 & $\mathrm{C}_{1}, \mathrm{C}_{2}, \mathrm{C}_{4}, \mathrm{C}_{3}, \mathrm{C}_{5}, \mathrm{C}_{6}$ \\
Codeword Shift 3 & $\mathrm{C}_{1}, \mathrm{C}_{2}, \mathrm{C}_{4}, \mathrm{C}_{3}, \mathrm{C}_{6}, \mathrm{C}_{5}$ \\
Codeword Shift 4 & $\mathrm{C}_{2}, \mathrm{C}_{1}, \mathrm{C}_{3}, \mathrm{C}_{4}, \mathrm{C}_{5}, \mathrm{C}_{6}$ \\
Codeword Shift 5 & $\mathrm{C}_{2}, \mathrm{C}_{1}, \mathrm{C}_{3}, \mathrm{C}_{4}, \mathrm{C}_{6}, \mathrm{C}_{5}$ \\
Codeword Shift 6 & $\mathrm{C}_{2}, \mathrm{C}_{1}, \mathrm{C}_{4}, \mathrm{C}_{3}, \mathrm{C}_{5}, \mathrm{C}_{6}$ \\
Codeword Shift 7 & $\mathrm{C}_{2}, \mathrm{C}_{1}, \mathrm{C}_{4}, \mathrm{C}_{3}, \mathrm{C}_{6}, \mathrm{C}_{5}$ \\
\hline \hline
\end{tabular}

\section{Result AND DisCUSSION}

In this section, the PAPR reduction performance of CSC will be evaluated through simulation. In the simulation, $N=128$ random input symbols are generated and they are all mapped using 64-QAM modulation. The OFDM signal being transmitted over AWGN channel. Cyclic prefix with the length of $1 / 4$ is added to the OFDM symbols in order to minimize the inter symbol interference (ISI) effect. In Table 2, shows the summarized of parameter that used in the MATLAB simulation process [16].

TABLE II

SiMULATION PARAMETER ON DOWNLINK OFDM MODULATION [16]

\begin{tabular}{lc}
\hline \multicolumn{1}{c}{ Parameter } & Value \\
\hline Channel Bandwidth & $1.25 \mathrm{MHz}$ \\
Sampling Frequency & $1.92 \mathrm{MHz}$ \\
Sub-carrier spacing & $15 \mathrm{kHz}$ \\
FFT size & 128 \\
Modulation technique & $64 \mathrm{QAM}$ \\
Cyclic Prefix & $1 / 4$ \\
Channel Model & Rayleigh Fading \\
\hline \hline
\end{tabular}

A. PAPR Analysis of Different Shifting Method for OFDM

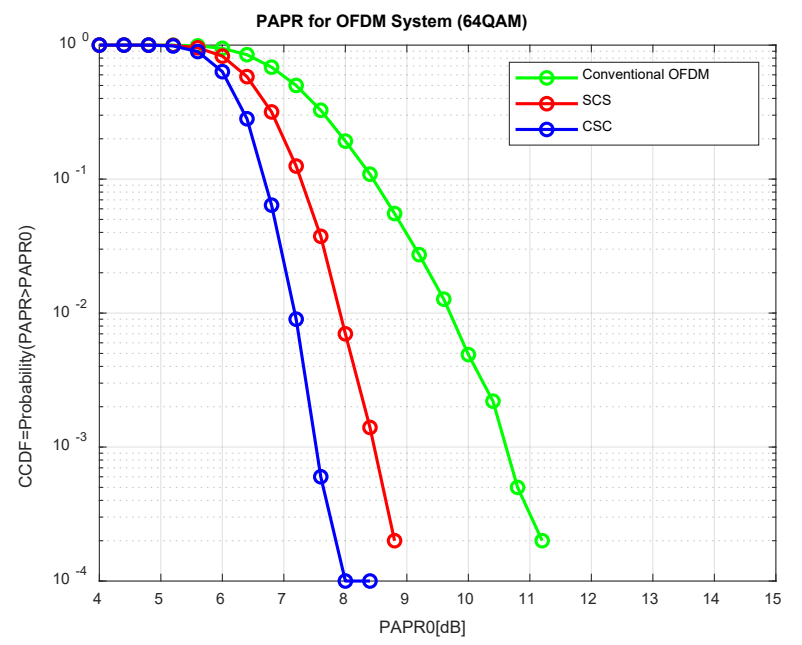

Fig. 3: PAPR Performance for CSC

TABLE III

PAPR ANALYSIS ON DIFFERENT CODEWORD SHIFTING METHOD

\begin{tabular}{ccc}
\hline \hline Method & PAPR (dB) & Improvement (\%) \\
\hline Conventional OFDM & 10.4 & - \\
SCS & 8.6 & 17.3 \\
CSC & 7.5 & 27.9 \\
\hline \hline
\end{tabular}

Fig. 3 shows the comparison of PAPR performance between conventional OFDM, Circulant Shift Codeword (SCS), and Cluster Scrambling Codeword (CSC). By comparing the results obtained at CCDF of $10^{-3}$, SCS give $17.3 \%$ improvement at 8.6 $\mathrm{dB}$ compared to the conventional OFDM. As in Table 3, apparently CSC manage to outperformed the PAPR reduction compared to other shifting method by $27.9 \%$ at $7.5 \mathrm{~dB}$. By altering the structure of the codeword has a significant impact on CSC PAPR performance. Hence, by reducing the distance of the codeword shifting, it can improve the performance of PAPR. The PAPR outperformed better with shorter codeword shift distance. By divided te codeword structure into a lower codeword distance compared to unaltered codeword as used in 
SCS technique, in shows that the lower distance lead to better PAPR performance.

\section{B. PAPR Analysis of Different Modulation Technique}

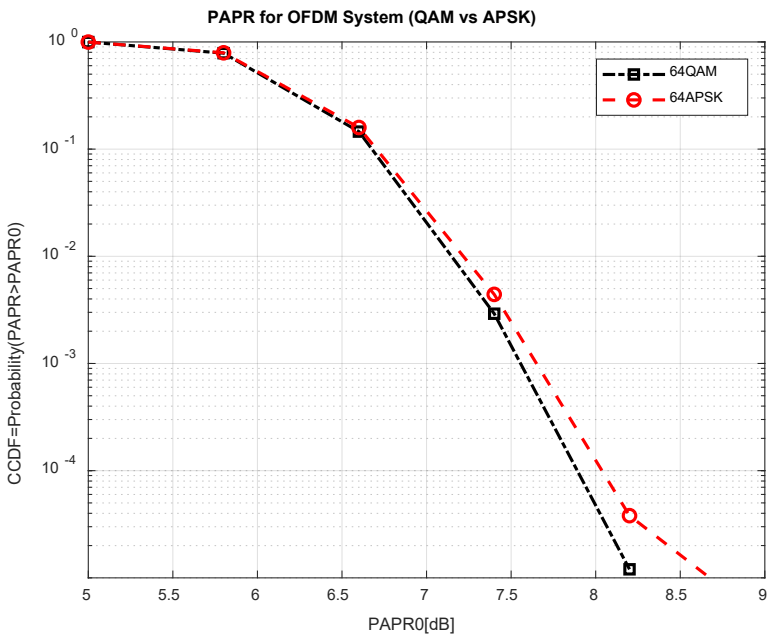

Fig. 4: PAPR Performance of Different Modulation Technique

TABLE IV

PAPR ANALYIS ON OFDM SYSTEM (64 QAM VS 64 APSK)

\begin{tabular}{ccc}
\hline \hline $\begin{array}{c}\text { Modulation } \\
\text { Technique }\end{array}$ & PAPR $(\mathrm{dB})$ & Improvement (\%) \\
\hline 64 QAM & 7.9 & - \\
64 APSK & 8.0 & 1.25 \\
\hline \hline
\end{tabular}

Fig. 4 shows PAPR performance comparison between 64 QAM and 64 APSK modulation technique using CSC method in OFDM system. Based on results obtained as in Table 4, 64 QAM gives outperformed better PAPR reduction compared to 64 APSK by $1.25 \%$ improvement at $8.0 \mathrm{~dB}$. By reffering to the results, since QAM modulation technique gives better performance and it is being considered to be implemented as input signal digital modution for the proposed shifting method.

\section{PAPR Analysis of OFDM vs F-OFDM}

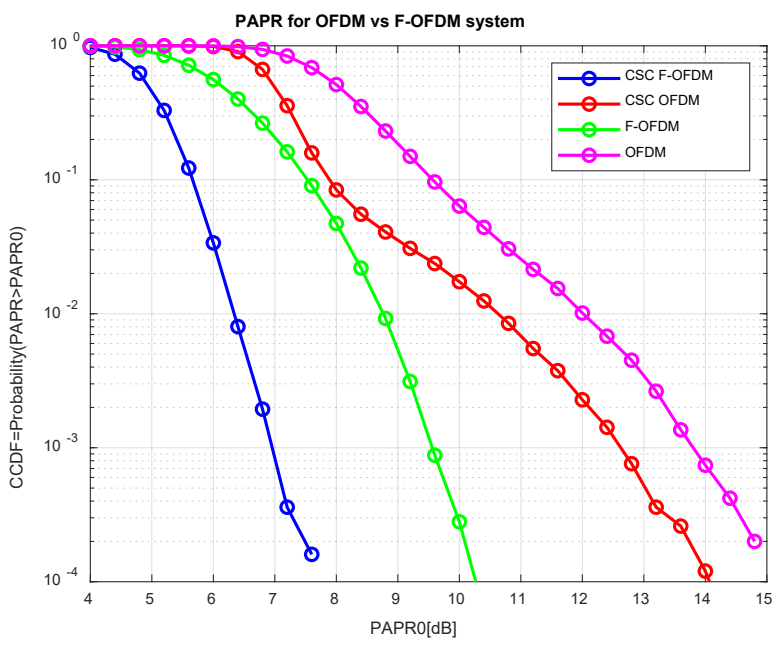

Fig. 5: PAPR Performance for CSC F-OFDM (64 QAM)
TABLE V PAPR ANALYSIS ON OFDM VS F-OFDM

\begin{tabular}{lcc}
\hline \hline \multicolumn{1}{c}{ System } & PAPR $(\mathrm{dB})$ & Improvement (\%) \\
\hline Conventional OFDM & 13.8 & - \\
Conventional F-OFDM & 9.6 & - \\
CSC OFDM & 12.7 & 7.97 \\
CSC F-OFDM & 7.0 & 27.08 \\
\hline \hline
\end{tabular}

As in Fig. 5 shows the PAPR performance on conventional OFDM and F-OFDM vs CSC technique. With this proposed method, the PAPR performance outperformed the conventional OFDM by $7.97 \%$ at $12.7 \mathrm{~dB}$ while CSC F-OFDM gives better performance compared to the conventional F-OFDM by $27.08 \%$ at $7.0 \mathrm{~dB}$ respectively as shown on Table 5 . By dividing the codeword structure into lower codeword distance, this may lead to better PAPR reduction. As the shifting process in CSC can generate alternative codeword, it gives flexibility to the system to select the one with the lowest PAPR for transmission.

\section{PAPR Analysis for Higher Order Modulation}

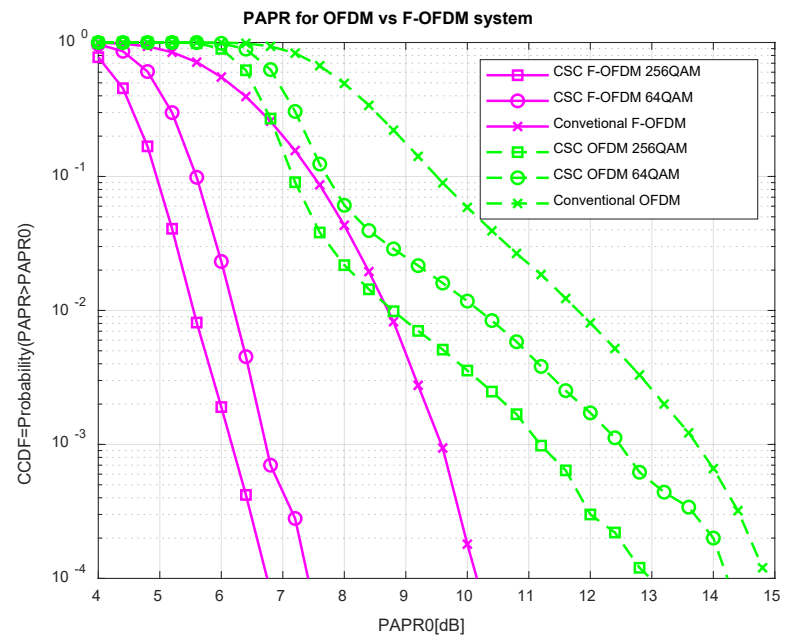

Fig. 6: PAPR Performance for Higher Order Modulation of CSC Technique

TABLE VI

PAPR ANALYSIS ON HIGHER ORDER MODULATION

\begin{tabular}{lcc}
\hline \multicolumn{1}{c}{ System } & PAPR $(\mathrm{dB})$ & Improvement (\%) \\
\hline Conventional OFDM & 13.7 & - \\
CSC OFDM (64 QAM) & 12.5 & 8.75 \\
CSC OFDM (256 QAM) & 11.2 & 18.24 \\
Conventional F-OFDM & 9.6 & - \\
CSC F-OFDM (64 QAM) & 6.8 & 2.92 \\
CSC F-OFDM (256 QAM) & 6.2 & 35.42 \\
\hline \hline
\end{tabular}

The Fig. 6 shows the PAPR performance of CSC technique in different modulation order for OFDM and F-OFDM system. By the proposed method, for OFDM system with 256 QAM gives better PAPR at $11.2 \mathrm{~dB}$ at $18.24 \%$ improvement compared to conventional OFDM and OFDM with 64 QAM which is $13.7 \mathrm{~dB}$ and $12.5 \mathrm{~dB}$ respectively. Meanwhile for F-ODFM system, with 256 QAM manage to outperformed the PAPR reduction of conventional F-OFDM and F-OFDM with 64 QAM by $35.42 \%$ improvement at $6.2 \mathrm{~dB}$. As shown in Table 6, apparently system with higher modulation order (256 QAM) gives better PAPR reduction performance. Refer to the PAPR 
performance obtained in different modulation order scheme, PAPR performed better for higher number of modulation order.

\section{CONCLUSION}

In this paper, the method proposed to deal with the high PAPR problem in F-OFDM system is called Cluster Scrambling Codeword (CSC) shifting technique have been performed and evaluated. By comparing the conventional OFDM and F-OFDM scheme with CSC scheme, the proposed method can provide significant improvement to the performance of PAPR value. Simulation results demonstrate that the proposed algorithm outperforms other evolutionary computation techniques by providing a better PAPR reduction of the $7.0 \mathrm{~dB}$ with $27.08 \%$ improvement compared to conventional F-OFDM system.

\section{ACKNOWLEDGMENT}

The authors would like to acknowledge the support and grateful to the Faculty of Electrical Engineering, Universiti Teknologi MARA (UiTM) Shah Alam, Selangor for providing the insight and expertise that greatly assist this research.

\section{REFERENCES}

[1] X. Yu, Y. Guanghui, Y. Xiao, Y. Zhen, X. Jun, and G. Bo, "FBOFDM : A Novel Multicarrier Scheme for 5G," Eur. Conf. Networks Commun., pp. 1-6, 2016.

[2] S. S. U. Shah et al., "Implementing enhanced MIMO with F-OFDM to increase system efficiency for future $5 \mathrm{G}$ cellular networks," Int. J. Commun. Networks Inf. Secur., vol. 10, pp. 403-409, 2018.

[3] X. Zhang, M. Jia, L. Chen, J. Qiu, D. Centre, and D. Centre, "FilteredOFDM - Enabler for Flexible Waveform in The 5th Generation Cellular Networks," in IEEE Global Communications Conference (GLOBECOM), 2015.

[4] C. Rajasekharl, D. Srinivasa, V. Y. Raghava, and D. Hanith, "PAPR Reduction performance in OFDM systems using Channel Coding Techniques," in International Conference on Electronics and Communication Systems, ICECS, 2014.

[5] A. Shukla and V. S. Nigam, "PAPR Reduction in OFDM System Based on SLM Technique," Int. J. Innov. Technol. Explor. Eng., vol. 3, no. 4, pp. 45-48, 2013.

[6] A. Chopra and K. Arora, "An Overview of Various Techniques to Reduce PAPR in SFBC MIMO OFDM Systems," Int. J. Eng. Trends Technol., vol. 9, no. 13, pp. 662-666, 2014.

[7] E. Abdullah, A. Idris, and A. Saparon, "Minimizing high PAPR in OFDM system using circulant shift codeword," J. Teknol. Sci. Eng., vol. 78, no. 2, pp. 135-140, 2016.

[8] M. D. Rozaini, A. Idris, D. M. Ali, and E. Abdullah, "Performance Evaluation of PAPR in OFDM System Using Median Codeword Shift and Hybrid Median Codeword Shift Method," Int. J. Electr. Electron. Syst. Res., vol. 14, 2019.

[9] K. G. Paterson and V. Tarokh, "On the Existence and Construction of Good Codes with Low Peak-to-Average Power Ratios," IEEE Trans. Inf. Theory, vol. 46, no. 51, pp. 1974-1987, 2000.

[10] P. Sharma and S. Verma, "PAPR Reduction of OFDM Signals using Selective Mapping with Turbo codes," Int. J. Wirel. Mob. Networks, vol. 3 , no. 4 , pp. 217-223, 2011.

[11] M. F. Naeiny, "Selected Mapping Algorithm for PAPR Reduction of Space-Frequency Coded OFDM Systems Without Side Information," IEEE Trans. Veh. Technol., vol. 60, no. 3, pp. 1211-1216, 2011.

[12] E. Abdullah, A. Idris, and A. Saparon, "PAPR Reduction Using SCS_SLM Technique in STFBC MIMO-OFDM," ARPN J. Eng. Appl. Sci., vol. 12, no. 10, pp. 3218-3221, 2017.

[13] N. Taspinar and M. Yildirim, "A Novel Parallel Artificial Bee Colony Algorithm and Its PAPR Reduction Performance Using SLM Scheme in OFDM and MIMO-OFDM Systems," IEEE Commun. Lett., vol. 19, no. 10, pp. 1830-1833, 2015.

[14] H. Y. Liang and H. Y. Jiang, "The Modified Artificial Bee ColonyBased SLM Scheme for PAPR Reduction in OFDM Systems," 1st Int. Conf. Artif. Intell. Inf. Commun. ICAIIC 2019, pp. 504-508, 2019.

[15] P. Boontra, T. Mata, and P. Boonsrimuang, "A Low Complexity PAPR Reduction for Space-Time Block Code MIMO-OFDM by using Modified-PTS with ABC-Concurrent Algorithm," Int. J. Intell. Eng. Syst., vol. 13, no. 1, pp. 57-64, 2020.

[16] J. Zyren, "Overview of the 3GPP Long Term Evolution Physical Layer," in Freescale Semiconductor, 2007.

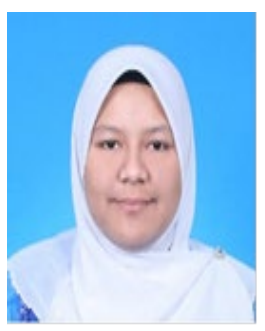

Aidatul Julia Abd Jabar is a $\mathrm{PhD}$ candidate at Faculty of Electrical Engineering, Universiti Teknologi MARA (UiTM). She was graduated her first degree from Universiti Teknologi Malaysia (UTM) in Bachelor of Electrical Engineering major in Telecommunication. She has received the Master of Engineering Telecommunication from Universiti Malaya (UM). Her research interests mainly focus on wireless communications, OFDM/ F-OFDM systems and power consumption reduction in wireless communications devices.

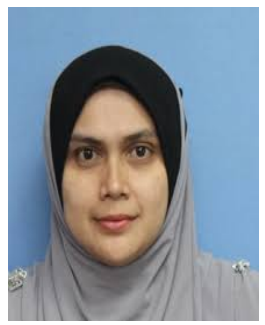

Azlina Idris is a Senior Lecturer at the Universiti Teknologi MARA (UiTM), Selangor, Malaysia. She obtained her $\mathrm{PhD}$ in wireless communication from University Malaya (UM), Malaysia. She has received the Master of Engineering in Electrical from Universiti Teknologi Malaysia (UTM). Previously, she obtained her first degree from Leeds Metropolitan University, United Kingdom with Honours, in Applied Computer. She is a member of Wireless Communication Technology (WiCOT) Research Interest Group (RIG) and her research interests include OFDM/OFDMA transmission, single and multiuser precoding, modulation, MIMO transmission techniques and receivers, channel coding, interference management and mitigation, and channel modeling (channel estimation). 